\title{
TURISMO DE NATURALEZA Y DESARROLLO SUSTENTABLE Y EN EL CAMPAMENTO TORTUGUERO "MAYTO"; COMO ACTIVIDADES COMPLEMENTARIAS A LA PROTECCIÓN DE LA TORTUGA MARINA
}

\section{TOURISM OF NATURE AND SUSTAINABLE DEVELOPMENT AND IN THE CAMPAMENTO TORTUGUERO "MAYTO"; AS COMPLEMENTARY ACTIVITIES TO THE PROTECTION OF MARINE TURTLE}

\author{
Melchor Orozco - Bravo ${ }^{1}$ \\ Angélica Beatriz Contreras Cueva ${ }^{2}$ \\ Javier Orozco - Alvarado ${ }^{3}$ \\ Quetzalli Orozco - Zepeda ${ }^{4}$
}

${ }^{1}$ Profesor investigador titular "B”, Universidad de Guadalajara, México. CUCEA.

${ }^{2}$ Profesora investigadora titular "C", Universidad de Guadalajara, México. CUCEA.

${ }^{3}$ Profesor investigador titular "C", Universidad de Guadalajara, México. CUCEA.

${ }^{4}$ Asistente investigación, Universidad de Guadalajara, México. CUCEA

Recibido: 11.12.17

Aprobado: 26.09.18

DOI:10.15517/isucr.v20i41.38781

\section{Resumen:}

La protección de la tortuga marina en México comenzó en los años sesenta, actividad que ha evolucionado caracterizando al país por el impulso de ésta en todos los estados con litoral, donde se implementan programas para la protección de este quelonio, operados, regulados y vigilados por las autoridades competentes. Sin embargo, aún existen problemas complejos que ponen en peligro a esta especie, lo que inspira a la sociedad y al gobierno a buscar herramientas para brindar una protección integral.

Es así como organizaciones sin fines de lucro llevan a cabo proyectos para investigar y proteger a la tortuga marina, con recursos propios además de los que se obtienen mediante donativos de empresas privadas.

En el municipio de Cabo Corrientes, en la localidad de Mayto, al sur del estado de Jalisco, se identifica uno de los programas de protección con mayor éxito en el país, con una vinculación importante con el sector privado, hoteles y restaurantes de la zona de influencia, y con las autoridades de todos los niveles dentro de las actividades de protección y conservación de las tortugas marinas.

Dicho programa, a cargo de la Universidad de Guadalajara, fue trasladado a este lugar en 2005, como una iniciativa de la Preparatoria Regional "Ignacio Jacobo Magaña" de Puerto Vallarta, y forma parte de la Red de Protección de la Tortuga Marina, creada en el mismo año, e impulsada por los Centros Universitarios de la Costa (CUCosta), de la Costa Sur 
(CUCsur), de Ciencias Biológicas y Agropecuarias (CUCBA) y del Sistema de Enseñanza Media Superior (SEMS).

La ubicación geográfica del Campamento Tortuguero Mayto, parte de la majestuosa Sierra Madre Occidental, es un área rica en recursos naturales con ambientes boscosos, selváticos, costeros, marinos e insulares, donde cada año anidan cientos de tortugas, y al cual emigran especies importantes como la Ballena Jorobada.

El objetivo de esta investigación, es desarrollar de manera conjunta con la población de Tehuamixtle, ubicada a cinco minutos del Campamento Mayto, la actividad turística sustentable, con el fin de mejorar el desarrollo de la protección de la tortuga marina aprovechándolo como detonante para impulsar la economía de la región, mediante el aprovechamiento turístico sustentable en conjunto con la pesca.

Estudios recientes elaborados por el gobierno municipal de Cabo Corrientes y por investigadores de la Universdiad de Guadalajara campus CUCosta, (Los retos del Turismo 2016) (Desarrollo Turístico y sustentabilidad 2008) (Turismo y desarrollo local en Máxico: el caso del municipio de Cabo corrientes en Jalisco, 2008), señalan que existe una deficiencia en la planeación turística, limitando el desarrollo económico incluyente y el aprovechamiento sustentable de los recursos naturales, generado por la anarquía para el desarrollo de espacios territoriales con potencial turístico.

A lo anterior, se promueve la generación de estrategias que permitan aprovechar los espacios turísticos, mediante la creación de políticas públicas para el desarrollo local. Desde una perspectiva alineada a las propuestas de la Organización Mundial del Turismo (OMT, 2002), se sostienen que se deben concretar acciones que involucren actores locales para aprovechar los recursos humanos y naturales de los espacios turísticos, y para lograr un desarrollo equilibrado se entiende que el turismo sostenible debe ser "un modelo de desarrollo económico concebido para mejorar la calidad de vida de la comunidad receptora, facilitar al visitante una experiencia de alta calidad y mantener la calidad del medio ambiente del que tanto la comunidad anfitriona como los visitantes dependen" (OMT, 2002).

Palabras clave: Protección Tortuga Marina; Turismo Ecológico; Desarrollo Regional; Desarrollo Comunitario;

\begin{abstract}
:
The protection of the sea turtle in Mexico began in the sixties, an activity that has evolved characterizing the country by its impulse in all the coastal states, where programs for the protection of this chelonian are implemented, operated, regulated and monitored by the competent authorities. However, there are still complex problems that endanger this species, which inspires society and the government to look for tools to provide comprehensive protection.

Keywords: Sea turtle; Mexico; Ecological tourism; Regional development; Community development;

\section{Introducción}

El desarrollo del turismo se considera como una actividad económica de gran relevancia en el ámbito local, regional, nacional, ecológico y de protección al medio ambiente, la preocupación actual de los gobiernos a nivel mundial se centra en el desarrollo sustentable y cuidado del medio ambiente, para lo cual promueven actividades como la protección de la tortuga marina y otras muchas especies animales y vegetales que se encuentran en peligro de extinción.
\end{abstract}


La mira central de esta investigación se ocupa de la protección de la tortuga marina, caso específico de la localidad de Mayto, ubicado en el municipio de Cabo Corrientes del estado de Jalisco, así como el desarrollo turístico ecológico en conjunto con la actividad pesquera para el mejoramiento de la calidad de vida en la región mediante el impulso al desarrollo económico.

Por lo anterior, para el desarrollo de turismo ecológico, se define como turismo sustentable aquel que protege y fomenta las oportunidades del futuro, al cubrir las necesidades de los turistas actuales y las regiones receptoras. Se concibe como una vía hacía la gestión de todos los recursos de forma que se puedan satisfacer las necesidades económicas, sociales y estéticas, respetando la integridad cultural, los procesos ecológicos esenciales, la diversidad biológica y los sistemas que sostienen la vida. (Orozco, 2008).

Por ende, se entiende que un proceso de desarrollo turístico sostenible local debe incluir una propuesta de desarrollo que sea: a) Biológicamente aceptable, respecto a las posibilidades y el entorno ecológico de la zona, b) socialmente admisible, involucra el apoyo de distintos actores sociales, que conlleve a la aceptación e integración de la sociedad en los proyectos de sostenibilidad.

Como estrategia de desarrollo local el turismo sostenible debe ser:

- Planificado: en la medida en que desarrolla una estrategia a partir de la información sobre diversas variables (económicas, sociales, naturales), que intervienen en el proceso turístico local, tomando en cuenta condiciones presentes y expectativas a futuro.

- Integrado: Considera variables económicas, socioculturales, institucionales y ambientales para el desarrollo de políticas y esquemas de planificación y gestión.

- Abierto: mantiene un carácter de intemporalidad y permite en cualquier momento la incorporación de nuevos espacios, nuevos recursos y nuevos agentes.

- Dimensionado: limita la afluencia de visitantes de acuerdo a las características físicas del espacio local, asegurando la capacidad de regeneración del territorio y la calidad de experiencia turística con una reducción de estacionalidad.

- Participativo: involucra el consenso de los agentes locales que intervienen en el proceso de desarrollo turístico.

- Duradero: involucra, de manera conjunta, el desarrollo económico con la conservación y el desarrollo del medio ambiente, lo que favorece una oferta turística local de calidad que potencialice los valores ambientales y socioculturales.

- Viable: mediante un desarrollo local económicamente y gestión de recursos eficiente que favorezca la conservación futura.

Con esto se justifica que las actividades del Campamento de Protección de la Tortuga Marina y su desarrollo turístico local tiene una gran interacción, por lo que se debe de desarrollar la explotación, el cuidado y bienestar de las comunidades locales, que fortalezca el interés de pobladores y visitantes por el cuidado del medio ambiente y la protección de las especies animales y vegetales, así como la interacción social comunitaria.

Los campamentos tortugueros son resultado de la perspectiva de planeación ambiental, enfocado en la protección e investigación de las tortugas, lo que genera una alternativa de desarrollo para poblaciones locales, y atracción de visitantes en busca de experiencias recreativas y de aprendizaje en convivencia con el ecosistema costero. 


\section{Metodología}

Con el uso del método analítico se identificarán los elementos que coexisten e interactúan en relación a la tortuga marina, como lo es el Campamento Tortuguero Mayto y los habitantes de Tehuamixtle, los visitantes al campamento tortuguero, actividades ecoturísticas, educación ambiental y socialización sobre el uso y manejo de recursos naturales, sin dejar de lado a las localidades aledañas, como los pescadores, para poder identificar los malos hábitos entre los pobladores y la explotación de las especies marinas, con la finalidad de poder elaborar propuestas de mejora.

Mediante la recolección de datos utilizando el método cualitativos, y que será por medio de entrevistas y encuestas se pretende conocer los hábitos de la población de Tehuamixtle que permitan identificar la fuente del problema con relación a la tortuga marina y el ecoturismo. Por otra parte esta información permitirá realizar estudios en el futuro para analizar el impacto económico relacionado con el desarrollo de la actividad turística, la pesca como principal actividad económica de la población, y la actividad del campamento.

En concreto, encontrar la causa por la que se genera la problemática entre pescadores, visitantes y la especie marina, para posteriormente determinar estrategias que permitan corregir las acciones negativas identificadas.

\section{Contexto \\ Cabo Corrientes}

Municipio situado al sureste del estado de Jalisco, en las coordenadas $20^{\circ} 10^{\prime} 55^{\prime \prime}$ a los $20^{\circ}$ $31^{\prime} 00^{\prime \prime}$ de latitud norte y de los $105^{\circ} 10^{\prime} 00^{\prime \prime}$ a los $105^{\circ} 41^{\prime} 25^{\prime \prime}$ de longitud oeste; a una altura de 1,085 metros sobre el nivel del mar. Colinda al norte con el océano Pacífico y el municipio de Puerto Vallarta; al este con Talpa de Allende y; al sur con Tomatlán y el océano Pacífico; al oeste con el océano Pacífico.

La mayor parte de su superficie está conformada por zonas accidentadas (72\%), con alturas que van de los 800 a los 1,800 metros sobre el nivel del mar; zonas semiplanas (20\%) compuestas por lomas y faldas de los cerros, con alturas de los 400 a los $800 \mathrm{msnm}$ y zonas planas (8\%), con alturas de los 0 a los $400 \mathrm{msnm}$.

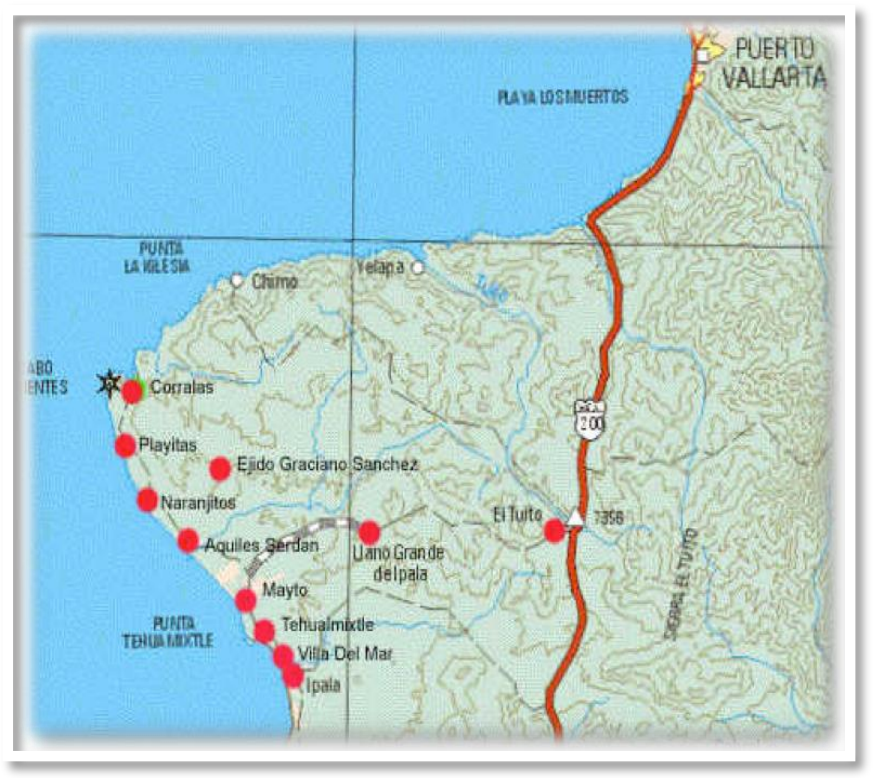

Figura 1: Campamento tortuguero Mayto 
Cabo Corrientes, cuenta con una diversidad de playas, unas ya muy conocidas por su cercanía con Puerto Vallarta destino turístico de talla internacional, como es el caso de las famosas tres perlas: Las Ánimas, Quimixto y Yelapa, también están Caletas, Majahuas y otras que aún no han sido tan explotadas, como son: Pizota, Chimo, Corrales, Mayto, Tehuamixtle, Villa del Mar, Peregrina de Gómez y algunas más. Cuentan con múltiples opciones de actividades, bien pueden ser acuáticas o de montaña.

\section{Tortugas marinas}

Entre el verano y principios de invierno, miles de tortugas marinas, "abarrotan" las playas del Pacífico mexicano, al depositar sus nidos sincronizadamente en un espectáculo natural conocido como "arribada", logrando México, la concentración más importante a nivel mundial de estos animales marinos, consideradas en peligro de extinción, siendo la bahía de Tehuamixtle y varios kilómetros de playas cercanas, famosas por la actividad del depósito de huevos en nidos in situ de las tortugas marinas.

Desafortunadamente la tortuga marina fue considerada como un recurso explotable ilimitado en las comunidades costeras para el aprovechamiento de su piel, carne, huevo y aceite la mayoría de los pescadores creció con la costumbre de consumirla como una accesible opción alimenticia y continuar con esta actividad en la actualidad a pesar de estar penada por la ley, presentándose de este modo en Tehuamixtle ${ }^{1}$ un comercio ilegal de carne de tortuga difícil de erradicar debido a la falta de vigilancia cercana a los lugares afectados, así como a la carencia de autoridades locales que sean especialistas en la materia y a la complejidad de acción por parte de las autoridades federales correspondientes, cuando se presentan estos casos de tráfico y robo.

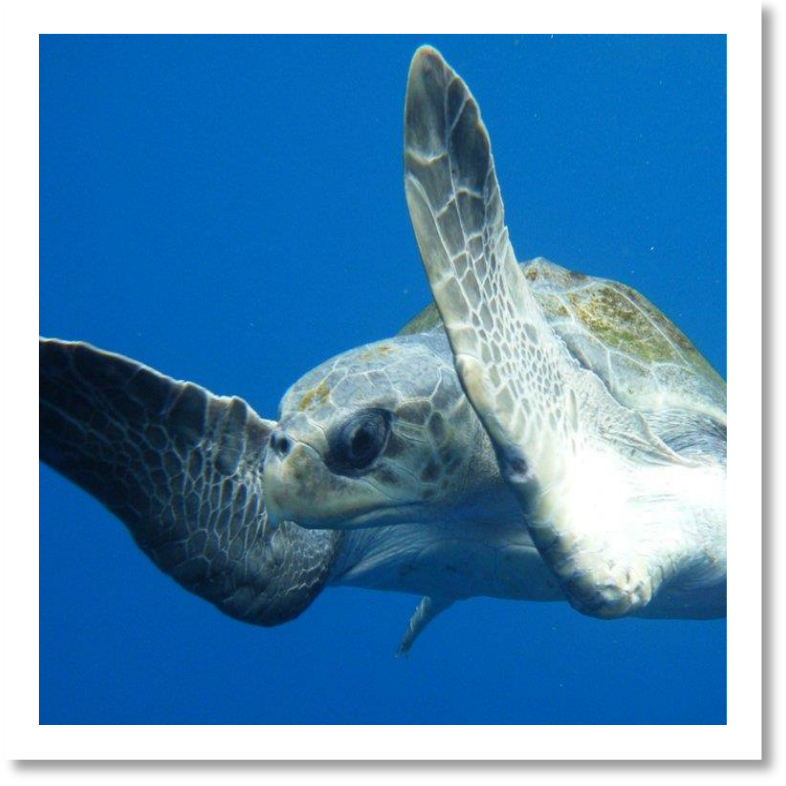

1 En este caso Tehuamixtle es la primer localidad que se estudia con respecto a estas actividades, aunque existen otras 9 poblaciones que también se ven afectadas y/o beneficiadas con el desarrollo de la protección de la tortuga marina por este campamento tortuguero, tales como: Villa del Mar, Mayto, Corrales, Aquiles Serdán, La Gorupa, entre otras. 
Figura 2: Elaboración propia

\section{Fauna}

\section{Algunos datos físicos del lugar}

El Campamento Tortuguero Playa Mayto inició operaciones desde el verano de 2005, entre sus principales labores se encuentran la de conservación de la Tortuga Marina en la zona costera de Cabo Corrientes, su área de acción son $12 \mathrm{kms}$ de playa semi-virgen, los cuales son patrullados cada noche para la búsqueda, detección y colecta de nidos, para lograr su incubación resguardada en corrales de anidación, que una vez eclosionados los huevos se liberan las crías, sin embargo el cuidado de las tortugas no se limita únicamente a las tortugas presentes en la playa sino también se extiende al cuidado y vigilancia a las tortugas encontradas o localizadas en mar abierto, ya sea atoradas en redes de pesca, capturadas en palangres líneas de pesca o que cuenten con algún tipo de limitación física que le impida su movilidad en el mar.

El campamento tortuguero Mayto ayuda a que la fauna se mantenga estable, al proporcionar información sobre dicha fauna a la población así como su interrelación con el medio ambiente, la diversidad de animales que coexisten en la región incluyendo hasta mamíferos tales como: venado cola blanca, mapaches, coatís, armadillos, zorrillos, zorros grises, coyotes, bastantes roedores y murciélagos, siendo estos últimos los principales mamíferos.

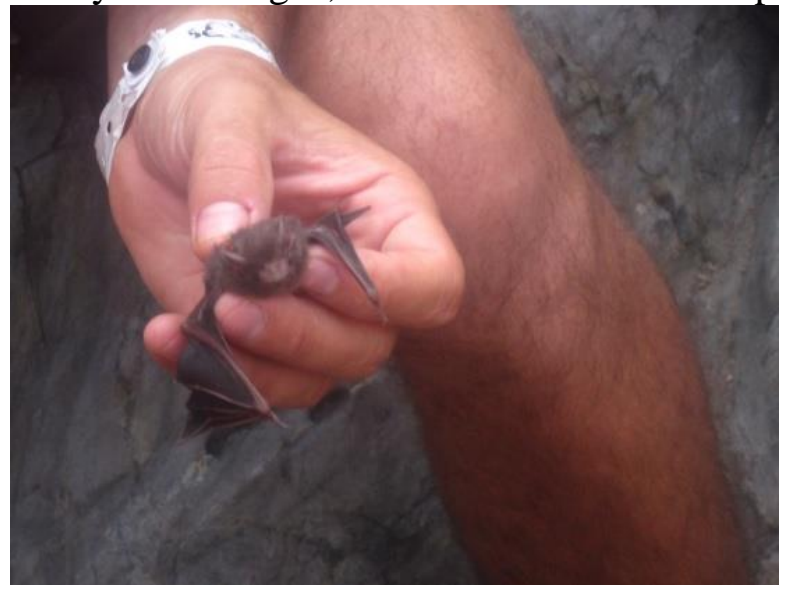

Figura 3: Colecta de especímenes. Elaboración propia

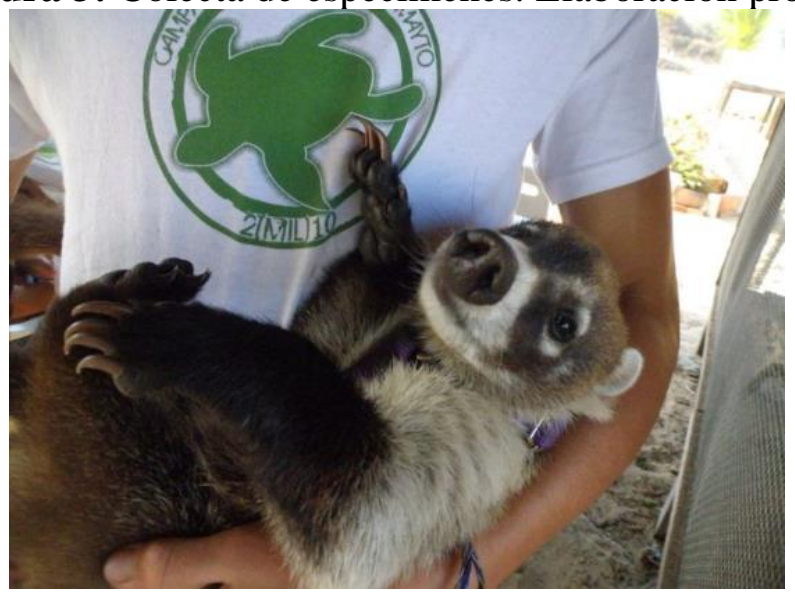

Figura 4: Elaboración propia 
También se pueden apreciar reptiles como: cocodrilos, el monstruo de Gila, iguanas verde e iguana negra y la iguana gigante, se pueden encontrar reptiles, como culebras ratoneras y boa lagartijera, coralillo y víbora de cascabel, mosquito, tarántula y por último, las tortugas marinas, a quien dedican la principal atención. Animales extraños como tilcuate, lagartijas, lagartija cola de látigo, una de las más vistas por esos rumbos.

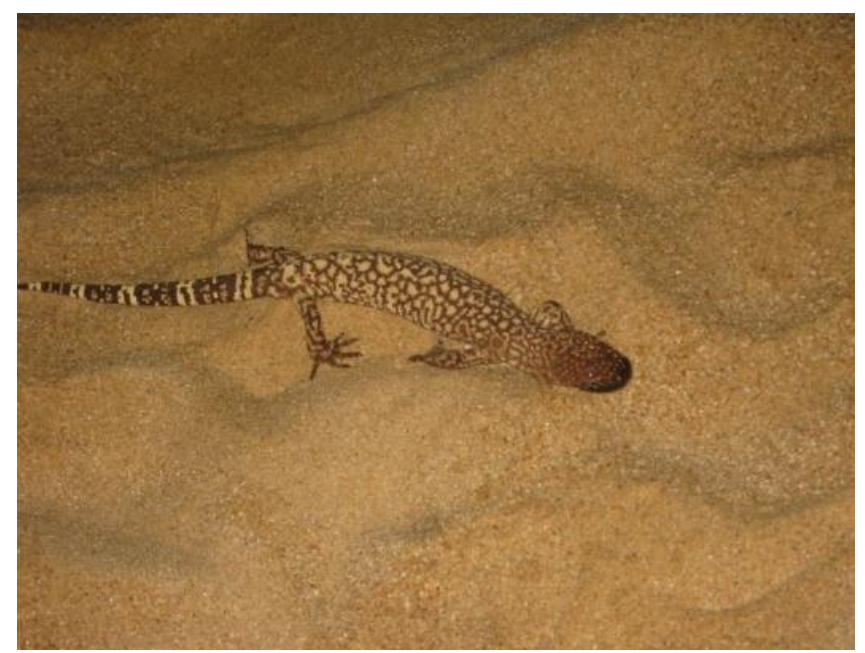

Figura 5: elaboración propia

La mayoría de las aves que llegan al estero son migratorias, permaneciendo por algunos días durante mayo en las costas. Suelen llegar en temporadas frías llegan aves como: garzas, águilas, grullas, espátula rosada así como patos de varios tipos. Otras aves de la región son el caracará plancus o quelele, gavilán, halcón y aguililla.

\section{Flora}

En la zona de Mayto predomina una vegetación halófita (debido a que es una zona semidesértica), estas especies se caracterizan por que crecen en la arena y toleran la salinidad de las aguas del mar estas plantas son: matorral espinoso, manglar, huisaches, arbustos de hojas escasas y muchas espinas, y el pastizal que en temporada de lluvia predomina, pero en la sequía es escaso.

\section{Campamentos tortugueros en México}

La organización de los primeros campamentos tortugueros estuvo a cargo del entonces Instituto Nacional de Investigaciones Biológico Pesqueras, del Instituto Nacional de la Pesca (hoy en día INP/SAGARPA), desde 1966 hasta 1999.

En 1991, el Gobierno de México, a través del Instituto Nacional de Ecología (INE), en ese entonces SEDUE, sustentado en un amplio marco de acciones jurídicas, normativas, de protección y conservación, formalizó un crédito con el Banco Mundial para operar el Programa Ambiental de México (PAM), que incluye el Subprograma Nacional de Protección y Conservación de Tortugas Marinas, el cual contemplaba en ese entonces, la instalación de campamentos tortugueros permanentes en 12 playas de 10 estados de la República Mexicana. Sin embargo, es hasta 1992, que dichos campamentos comenzaron a trabajar de manera formal, realizando actividades de protección y conservación a través de recorridos en playas, 
con el propósito de recolectar y transplantar nidos, sembrar huevos en corrales de incubación y liberar crías, acciones que han permitido salvaguardar a cientos de quelonios de las siete especies de tortugas marinas que habitan los mares mexicanos:

1. Golfina (Lepidochelys olivacea)

2. Laúd (Dermochelys coriacea)

3. Prieta (Chelonia agassizii)

4. Lora (Lepidochelys kempi)

5. Verde o Blanca (Chelonia mydas)

6. Caguama o Perica (Caretta caretta)

7. Carey (Eretmochelys imbricata).

En 2001, en conformidad con el artículo 28 - fracción XVII del Reglamento Interior de la Semarnat (D.O.F. 04/06/2001) y el artículo 38 de la Ley General de Vida Silvestre (D.O.F. 03/07/2000), por primera vez en México se integra en un solo programa a cargo del Gobierno Federal, la operación de 28 campamentos tortugueros, ahora denominados Centros para la Protección y Conservación de las Tortugas Marinas (CPCTM), los cuales son:

1. Tecolutla, Veracruz

2. Centro Mexicano de la Tortuga, Oaxaca

3. Chenkan, Campeche

4. La Escobilla, Oaxaca

5. X'Cacel, Q. Roo

6. Morro Ayuta, Oaxaca

7. Mahahual, Q. Roo

8. Barra de La Cruz, Oaxaca

9. Platanitos, Nayarit

10. Rancho Nuevo, Tamaulipas

11. Mismaloya, Jalisco

12. Miramar, Tamaulipas

13. Chalacatepec, Jalisco

14. Altamira, Tamaulipas

15. Boca de Apiza, Colima

16. Playa Dos/Barra del Tordo, Tamaulipas

17. Mexiquillo, Michoacán

18. Lechuguillas, Veracruz

19. Piedra de Tlacoyunque, Guerrero

20. Isla Aguada, Campeche

21. Tierra Colorada, Guerrero

22. Las Coloradas, Yucatán

23. Chacahua, Oaxaca

24. El Verde, Sinaloa

25. Puerto Arista, Chiapas

26. Mayto, Cabo Corrientes, Jalisco

27. Bahía de Los Ángeles, Baja California

28. Nuevo Vallarta, Nayarit 


\section{Campamento Tortuguero Mayto y su vínculo con la localidad de Tehuamixtle}

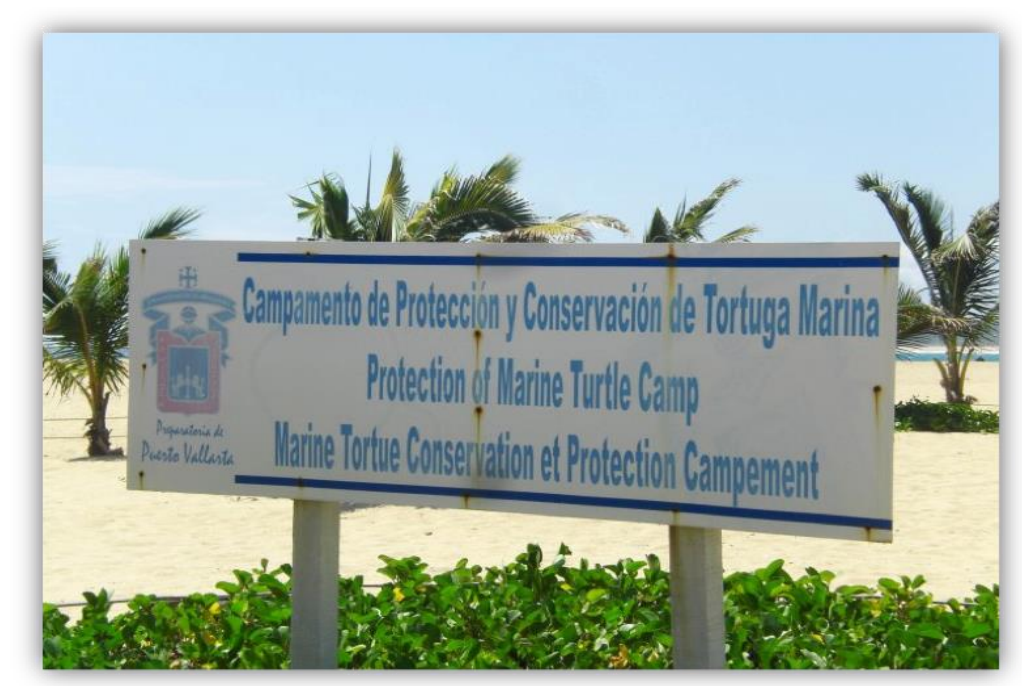

Figura 6: Elaboración propia

La afluencia de turistas que arriban a la playa de Tehuamixtle ha sido de gran importancia para la economía del lugar, una razón por la cual en los últimos años ha tenido más concurrencia la población costera, esta ha sido por la instalación del campamento tortuguero que está a 5 minutos del lugar, en la localidad de Mayto en el cual tienen como objetivo principal la protección, rescate y cuidado de la Tortuga marina.

El Campamento de Protección y Conservación de Tortuga Marina Mayto está a cargo de la Universidad de Guadalajara (por conducto de la Preparatoria Regional de Puerto Vallarta, “Jacobo Magaña”), y el proyecto es coordinado por el Biólogo Israel Llamas González.

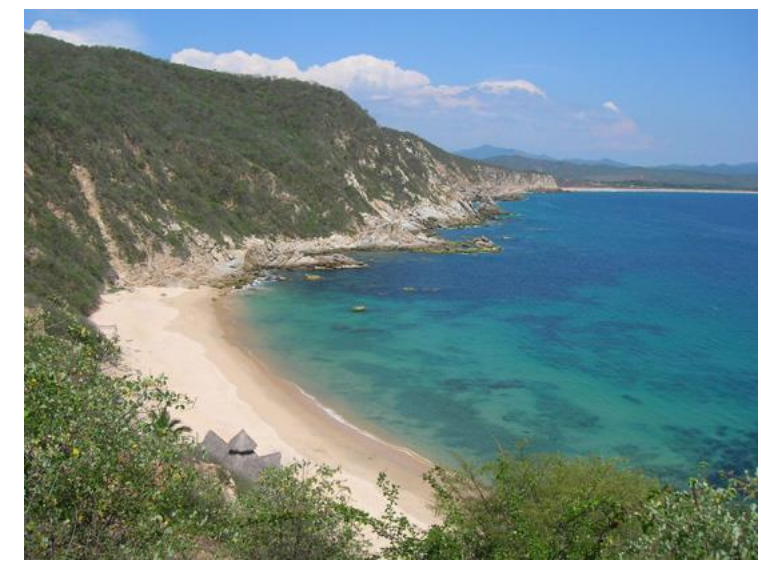

Figura 7: Elaboración propia

\section{Modificaciones en la vida de los pobladores de Tehuamixtle, por sus actividades}

Tehuamixtle es una de las poblaciones que conforman el municipio de Cabo Corrientes, entre sus actividades económicas más importante está la pesca, ya que se refiere como actividad 
económica principal, esta se lleva a cabo frente a la playa de anidación de Mayto y en las áreas de reproducción y forrajeo de cuatro especies de tortuga marina, presentes en la zona, siendo estos pescadores quienes tienen mayor contacto con las tortugas en altamar y mayor oportunidad de interactuar con ellas proporcionándoles ayuda o atención especial hacia aquellas que lo requieran generando la oportunidad de seguir su vida.

Sin embargo, a pesar de ello y debido a que hace 30 años aproximadamente la tortuga marina fue considerada como un recurso explotable ilimitado ${ }^{2}$ en las comunidades costeras para el aprovechamiento de su piel, carne, huevo y aceite, la mayoría de los pescadores creció con la costumbre de consumirla como una accesible opción alimenticia y continuar con esta actividad en la actualidad a pesar de estar penada por la ley Federal, presentándose de este modo en Tehuamixtle, un comercio ilegal de carne de Tortuga, el cual ha sido difícil de erradicar debido a la carencia de intervención por parte de las autoridades locales, estatales, así como a la complejidad de acción oportuna por parte de las autoridades federales correspondientes.

Desgraciadamente, como consecuencia de esta mala costumbre, en la mayoría de las ocasiones los pescadores abusando de sus artes de pesca al capturar accidentalmente una tortuga ya sea en sus redes o líneas de pesca eligen su sacrificio en lugar de liberarlas de nuevo al mar.

A pesar de este tipo de involucramiento de la comunidad pesquera de Tehuamixtle con las labores de protección del Campamento Tortuguero, sigue habiendo persistencia de algunos pescadores en la captura y sacrificio de tortugas para su consumo, lo cual desalienta a nuestro programa de concientización en la población local, más sin embargo, sí se ha logrado sembrar la semilla de conciencia en otros, quienes otorgan un valor más elevado a una tortuga viva para su observación que a una tortuga muerta para ser servida en estofado como platillo alimenticio.

\section{Actividades económicas de Tehuamixtle que se han modificado}

La flota pesquera de Tehuamixtle, es la única opción presente en la zona y es quien ha proporcionado el servicio del transporte para los grupos que visitan el campamento tortuguero Mayto, utilizando sus lanchas de pesca para trasladar a cientos de jóvenes a altamar (que cada año arriban al campamento para apoyar las actividades de rescate y protección de la Tortuga), en sus diferentes opciones, visitantes, practicantes, investigación, voluntarios, prestadores de servicio social, intercambio, tesistas, entre otros, provenientes de diferentes escuelas y universidades tanto nacionales como internacionales, cuyas actividades es llevar a cabo avistamiento de Tortuga para complementar el conocimiento biológico, del quelonio, esta actividad es realizada frente a la bahía de Tehuamixtle.

2 Como muchos otros recursos naturales que han sido sobreexplotados y exterminados o minados considerablemente su existencia. 


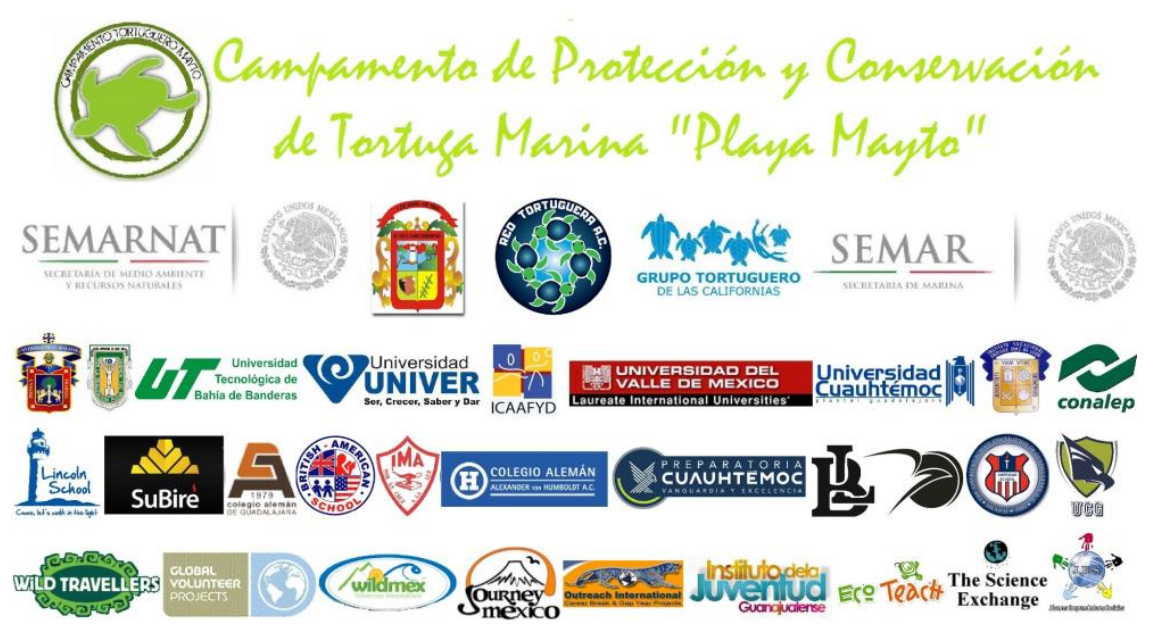

Figura 8: Actores involucrados

A consecuencia del arribo de cientos de visitantes principalmente estudiantes tanto nacionales como extranjeros, una de las principales actividades base de la economía de Tehuamixtle como lo ha sido la pesca se ha venido modificando, ya que anteriormente las personas que habitan en esta area, se dedicaban exclusivamente a la pesca y a la captura de la tortuga marina, hoy en día los lancheros prestan sus servicios para llevar a los turistas, visitantes y estudiosos a altamar para realizar avistamientos y observación de las tortugas.

A lo largo de 7 años los pescadores de Tehuamixtle han puesto sus lanchas al servicio del Campamento para realizar esta actividad ecoturística a un costo moderado, considerando que las distancias recorridas son muy cortas (debido a la fácil ubicación de las tortugas cerca de la costa) y a que el pescador no desarrolla un esfuerzo físico considerable (a comparación del trabajo realizado para recoger una red de pesca) de manera que en tan solo un par de horas sirviendo como operador de la embarcación un pescador puede obtener la ganancia de hasta 8 horas de trabajo pesado en altamar.

Actualmente, al año se reciben un promedio de 20 a 30 grupos que van desde los 10 hasta los 45 integrantes por grupo, en la localidad de Tehuamixtle, para llevar a cabo los recorridos en altamar, se contratan de una hasta cuatro lanchas para realizar el tour, el pago por cada embarcación es de \$600.00 aproximadamente, (sin contar el pago al guía) proporcionando al poblado pesquero una derrama económica que viene a apoyar a las familias de la localidad, generada por el atractivo natural de las tortugas marinas en una temporada que va durante los meses de Junio a Febrero o en algunas ocasiones hasta marzo.

A pesar de este tipo de involucramiento de la comunidad pesquera de Tehuamixtle con las labores de protección y apoyo al Campamento Tortuguero, siguen existiendo algunos pescadores que se dedican a la captura y sacrificio de tortugas para su consumo y venta illegal, lo cual ha sido una lucha constante de nuestro programa de concientización en la población local, a pesar de todo ello, sí se ha logrado cambiar la idea de capturar y sacrificar a esta especie en peligro de extinción, ya que se ha dado un valor agregado a dejar con vida al quelonio y ellos son quienes otorgan ese valor más elevado a una tortuga viva para su observación que a una tortuga muerta. 


\section{Discusión y análisis \\ El Turismo y el Medio Ambiente}

El turismo es en la actualidad una de las ramas más importantes del sector servicios y de las de mayor crecimiento a nivel mundial. En 2012 generó una demanda de pernoctaciones internacionales por más de mil millones de visitantes, logrando un incremento del $4 \%$ con respecto a 2011, generando un ingreso por 1 Billón, 75 mil millones de dólares estadounidenses, logrando un crecimiento de $4.2 \%$ más que el año anterior (2011).

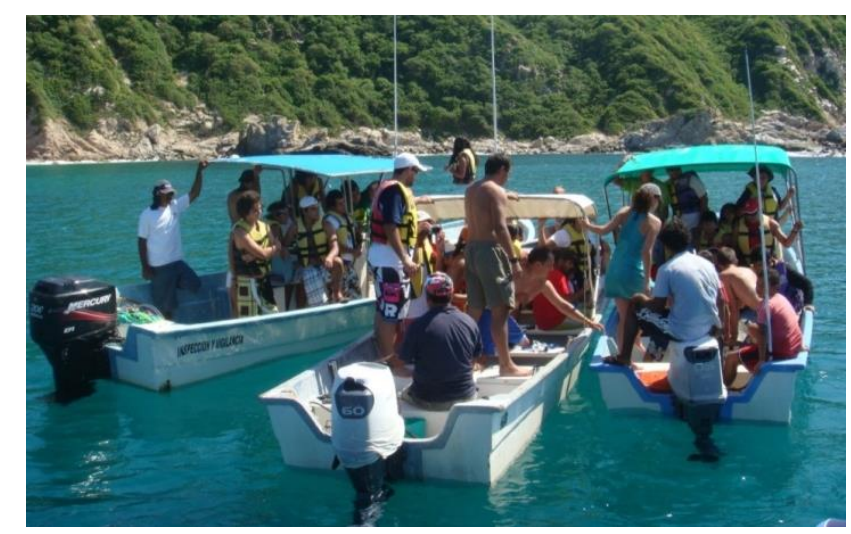

Figura 9: Elaboración propia

Los ingresos turísticos representaron más del $8 \%$ de las exportaciones mundiales de bienes y un tercio del comercio de servicios; la actividad absorbió el $10.7 \%$ de todo el capital invertido y el $6.9 \%$ del total del gasto publico mundial.

El turismo ha representado una actividad importante para la economía mundial, pero no siempre se ha llevado a cabo una adecuada planificación, pues se ha convertido en un constante depredador del medio ambiente natural; No solo ha transformado el aspecto físico de las zonas turísticas, sino que ha generado graves trastornos ecológicos: destrucción de ecosistemas, disminución de la cantidad y calidad del agua, empobrecimiento y contaminación de los suelos, extinción de múltiples especies de la fauna, afectación severa de la flora, depredación pesquera y contaminación de mar, así como desintegrador de actividades económicas tradicionales, aculturación, migración, fenómenos de crecimiento poblacional y urbano desordenado, falta de servicios públicos, entre otros.

De acuerdo a los datos de la Organización Mundial de Turismo (OMT), el segmento turístico que actualmente experimenta el más acelerado crecimiento es el llamado turismo "alternativo", es decir el turismo que tiene como destino la naturaleza y que incluye todas aquellas practicas turísticas conocidas como turismo especializado: turismo de aventura, científico, cinegético, montañismo, campismo, buceo, safarí fotográfico, canotaje, espeleología, ecoturismo, entre otros.

A pesar de que México cuenta con condiciones en extremo favorables para el despliegue de las nuevas actividades que conforman el turismo alternativo (variedad y diversidad geográfica, climatológica y de suelos; la presencia de muchos y muy variados ecosistemas; grandes atractivos naturales y una enorme riqueza cultural) el modelo turístico impulsado por el gobierno y el capital nacional y extranjero es el convencional y su crecimiento ha descansado fundamentalmente en los llamados centros integralmente planeados (Cancún, Ixtapa, Bahía de Huatulco) que implican el desarrollo a gran escala de zonas hoteleras, áreas 
de recreo y zonas comerciales y, en menor medida, en la consolidación o fortalecimiento de los centros tradicionales de playa. Solo recientemente, la Secretaría de Turismo y un conjunto de operadores privados se han preocupado por desarrollar el turismo alternativo.

Efectivamente, la creciente contaminación de la atmósfera, los suelos y el agua; la perdida de múltiples especies de la flora y la fauna; la destrucción de la capa de ozono etc. que en conjunto y a largo plazo representan un peligro para la sobrevivencia humana, pero que en lo inmediato se traducen en una pérdida de la calidad de vida, han sido determinantes para que en los últimos 20 años surgieran los movimientos sociales conservacionistas, ecologistas y ambientalistas y para que entre los gobiernos y las poblaciones en general, se haya empezado a buscar y en algunos casos adoptar, nuevas formas de desarrollo que se adecuen por una parte a los requerimientos de transformación y aprovechamiento de la naturaleza y por la otra, a la necesidad de su conservación como condición para preservar la propia existencia humana. Es en este marco que surge el concepto de desarrollo sustentable.

No obstante, la creciente utilización del concepto no existe una solo visión de lo que es el desarrollo sustentable. Para algunos alcanzar un desarrollo sustentable es lograr el crecimiento económico continuo mediante un manejo más racional de los recursos naturales y la utilización de tecnologías más eficientes y menos contaminantes.

El campamento Mayto es sin duda un gran apoyo dentro del sector ecológico de Jalisco, pero además representa un factor importante dentro del turismo local, pues atrae grupos de estudiantes y personas voluntarias (turismo de naturaleza) para la conservación y cuidado de las tortugas, así como de otras especies e incluido el cuidado del medio ambiente en general. Tehuamixtle a su vez, es una comunidad donde el turismo es parte importante dentro de su economía, ya que la mayoría de sus ingresos monetarios se obtiene de esta actividad, que sin duda, deja mayores ganancias económicas que las demás actividades que se realizan en la región como lo es la pesca.

Gracias a los turistas, los pequeños establecimientos de alimentos y bebidas que permanecen en la playa, pueden continuar generando cada vez una mayor demanda y de esta forma mejorar el servicio que se les brinda.

También, los pescadores han encontrado en sus lanchas otra forma de ingreso, ya que las utilizan como medio de transporte para que los turistas puedan disfrutar de observar a las tortugas y delfines en su hábitat natural.

De esta forma, nos damos cuenta que el turismo se ha desarrollado con el tiempo y la implementación de nuevos atractivos dentro de la región, sin dejar a un lado el cuidado de los animales y la preservación del ambiente natural.

Podemos decir que con el proyecto del Campamento Tortuguero Mayto se tiene una experiencia inolvidable, ya que se aprenden muchas cosas nuevas que sin duda nos servirán en el futuro. Casi siempre escuchamos de la gente que destruye la naturaleza, que no la respeta y las actividades de este campamento nos muestra que también existe gente que está muy preocupada por la salvaguardia de especies, tales como son las tortugas marinas y el respeto del ambiente y su entorno.

Esperemos que muchas generaciones futuras se interesen y asistan en este tipo de proyectos, para que el campamento tenga el éxito esperado y logre sobrevivir a sus actividades y que sus ideas se transmitan de generación en generación, para que ellos estén orgullosos de lo que les dejamos y que se den cuenta de que es importante cuidar de la naturaleza y su entorno. Por otra parte resulta también muy interesante encontrar que la gente que vive en las localidades aledañas al campamento, han logrado superar un poco la etapa de la explotación de la tortuga y saqueo de nidos de las tortugas, esto ha logrado que ellos tengan una visión 
diferente sobre la protección de la tortuga y las actividades de recreación que se realizan con los visitantes al campamento, y en general le gustan mucho lo que están haciendo y la repercusión del campamento en el turismo.

El responsable del Campamento, el Biólogo Israel Llamas, ha realizado el trabajo diario por conservar una especie en peligro de extinción como la tortuga marina y el rescate de sus huevos, en compañía de un grupo de voluntarios del poblado de Mayto, así como personal de servicio social, tesistas de pregrado, posgrado y estudiantes de intercambio tanto nacionales como internacionales.

Siembras del huevo de la tortuga

\begin{tabular}{|llllll|}
\hline TEMPORADA & $\begin{array}{c}\text { NIDOS } \\
\text { COLECTADOS }\end{array}$ & $\begin{array}{c}\text { NIDOS } \\
\text { SAQUEADOS }\end{array}$ & $\begin{array}{c}\text { HUEVOS } \\
\text { SEMBRADOS }\end{array}$ & $\begin{array}{c}\text { CRIAS } \\
\text { LIBERADAS }\end{array}$ & $\begin{array}{c}\text { PORCENTAJE } \\
\text { DE ECLOSION }\end{array}$ \\
\hline 2005 & 502 & s/d & 47,432 & 39,843 & $84 \%$ \\
\hline 2006 & 801 & 200 & 76,522 & 61,982 & $80.95 \%$ \\
\hline 2007 & 985 & 225 & 93,399 & 74,719 & $79.90 \%$ \\
\hline 2008 & 882 & 277 & 84,920 & 63,944 & $75.30 \%$ \\
\hline 2009 & 445 & 450 & 41,385 & 30,086 & $72.70 \%$ \\
\hline 2010 & 522 & 102 & 49,590 & 13,187 & \\
\hline TOTAL & $\mathbf{4 , 1 3 7}$ & $\mathbf{1 , 2 5 4}$ & $\mathbf{3 9 3 , 2 4 8}$ & $\mathbf{2 8 3 , 7 6 1}$ & $\mathbf{7 9 \%}$ \\
\hline
\end{tabular}

Fuente: Elaboración propia.

Para ello mostramos algunas estadísticas sobre la colecta y siembra del huevo de tortuga marina que se lleva a cabo en dicho campamento.

\section{Diagnóstico de la problemática enfrentada en términos ambientales y sociales}

Todas las especies de tortugas marinas son consideradas en la categoría de "En Peligro de Extinción" de acuerdo a la Unión Internacional para la Conservación de la Naturaleza (IUCN) por sus siglas en inglés, (IUCN, 2000). La IUCN define como especie en peligro de extinción a aquella cuya supervivencia es poco probable si los factores causales continúan operando, e incluye especies cuyos números han sido drásticamente reducidos.

La Convención en Comercio Internacional en Especies Amenazadas de Flora y Fauna (CITES) por sus siglas en inglés, enlista a todas las tortugas marinas en el "Apéndice I", en el cual se encuentran las especies más susceptibles a la extinción y que por lo tanto no pueden ser comercializadas, desde o hacia países signatarios de la convención (CITES, 2004). De acuerdo a la Norma Oficial Mexicana NOM-059-ECOL-2001 (DOF, 2001), las 7 especies de tortugas marinas presentes en México: la tortuga golfina (Lepidochelys olivacea), la lora (Lepidochelys kempii), la laúd (Dermochelys coriacea), la tortuga prieta (Chelonia agassizii), la tortuga verde o blanca (Chelonia mydas), la carey (Eretmochelys imbricata) y la tortuga amarilla o caguama (Caretta caretta) se encuentran en la categoría de "En Peligro de Extinción". 
La NOM-059-ECOL-2001 (DOF, 2001), define como especie en Peligro de Extinción a aquellas especies cuyas áreas de distribución o tamaño de sus poblaciones en el territorio nacional han disminuido drásticamente poniendo en riesgo su viabilidad biológica en todo su hábitat natural, debido a factores tales como la destrucción o modificación drástica del hábitat, aprovechamiento no sustentable, enfermedades o depredación, entre otros (esta categoría coincide parcialmente con las categorías en peligro crítico y en peligro de extinción de la clasificación de la IUCN). Como medida de manejo en México se decretó la "Protección de Zona de Anidación y Desove" (DOF 8 de enero de 1986), la veda total para las especies y subespecies de tortugas marinas y la prohibición de posesión o consumo de huevo, carne o piel (DOF 31 de mayo 1990). Por otro lado, se publicó una Norma Oficial Mexicana que obliga al uso de dispositivos excluidores de tortuga (DET) en las redes de arrastre camaroneras NOM-002-PESC-1996 (DOF, 1996).

Muestra de anidación. Elaboración propia

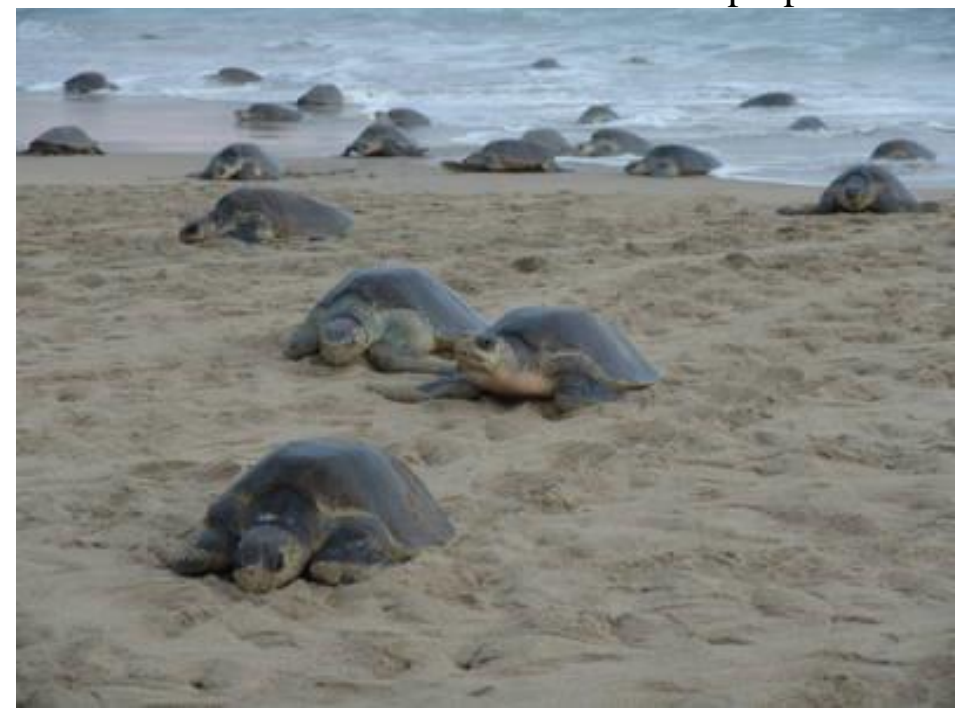

En muchas playas del Pacífico Mexicano en las que anidan tortugas marinas, existen campamentos tortugueros operados por gobiernos municipales, estatales, federales, universidades, organizaciones no gubernamentales e iniciativa privada, incluyendo la industria hotelera.

Sin embargo, por mucho tiempo, la tortuga golfina constituyó una de las poblaciones más abundantes, aunque hoy en día está sumamente mermada, debido a la explotación excesiva de la que fue y ha sido objeto.

El papel que ha jugado la zona costera de Jalisco, en la alimentación y nacimiento de las tortugas marinas, era poco conocido hace 10 años, pero hoy en día sabemos de la trascendental importancia del papel que juega el Estado; Dentro de las ocho especies de tortugas marinas que hay en el mundo, cuatro se alimentan o anidan en la región de Cabo Corrientes: la tortuga golfina, la laúd, la Carey y la tortuga prieta.

Es notorio que la situación de peligro de extinción de todas las especies de tortugas marinas no sólo se debe a la sobre-explotación, sino que este deterioro poblacional se ha agudizado por cuatro razones principales:

a) Por la explotación ilegal de sus productos.

b) Por la acelerada presión negativa hacia los ecosistemas marinos, resultado del progreso de una civilización consumista y productora de basura y contaminantes. 
c) Finalmente es la captura incidental que causa la muerte de tortugas marinas por el uso de diversas artes de pesca, siendo las más importantes las de redes de arrastre de fondo para peces y camarones, los palangres para tiburones y para picudos, los trasmallos y la captura que se efectúa con los chinchorros playeros y con líneas de anzuelos.

d) Aunado a lo anterior, el encuentro del desarrollo en las zonas costeras que ha resultado de la transformación de las playas, y su degradación al aumentar el número de edificaciones de hoteles y desarrollos turísticos. Estando entre los principales afectados las tortugas marinas debido a que las estructuras hechas por el hombre bloquean el paso a las hembras cuando salen a anidar, compactan la arena en todos sus sectores, modifican el movimiento natural de la arena a lo largo de la costa, lo cual afecta el ciclo de vida de las diferentes especies.

\section{Acciones implementadas para lograr los objetivos}

1. Protección de tortugas marinas y sus nidos, determinar las especies anidadoras y las zonas con mayor anidación.

2. Identificar los factores que impiden el éxito de la anidación de las tortugas marinas.

3. Atención de tortugas marinas heridas y/o enfermas para su recuperación y posterior liberación.

4. Concientizar y promover cambios de hábitos en la población a través de la educación ambiental.

5. Promover las actividades de difusión sobre la importancia de las tortugas marinas y la búsqueda de alternativas para su protección y conservación.

6. Creación y Capacitación de grupos de trabajo y voluntarios.

7. Promover y desarrollar proyectos de investigación de la zona.

8. Mitigar los factores identificados que impiden el éxito de la anidación de las tortugas marinas.

9. Tener un conocimiento amplio sobre la población anidadora de tortugas marinas en la zona del Municipio de Cabo Corrientes para llevar a cabo acciones y estrategias concretas para la conservación de la especies.

\section{Programas y actividades en el campamento}

1. Paseo en altamar para el avistamiento de tortugas y dar su explicación fisiológica, medirla, pesarla y marcarla.

2. Colecta de nidos: patrullaje a pie o en cuatrimotos por brigadas de estudiantes dirigidos por el personal del campamento.

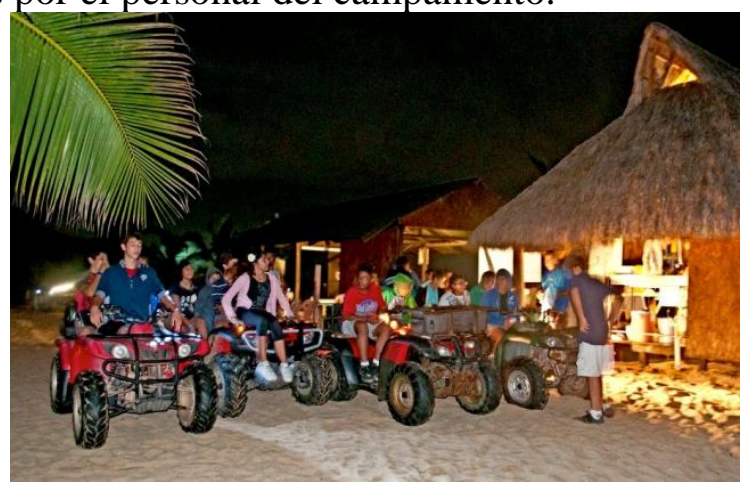

Figura 10: Tour por las instalaciones 
3. Se realiza el llenado de ficha: numero de huevos, profundidad del nido, distancia desde la marea alta y temperatura; el nido colectado se transporta en bolsas especiales (de lona principalmente) hasta el campamento.

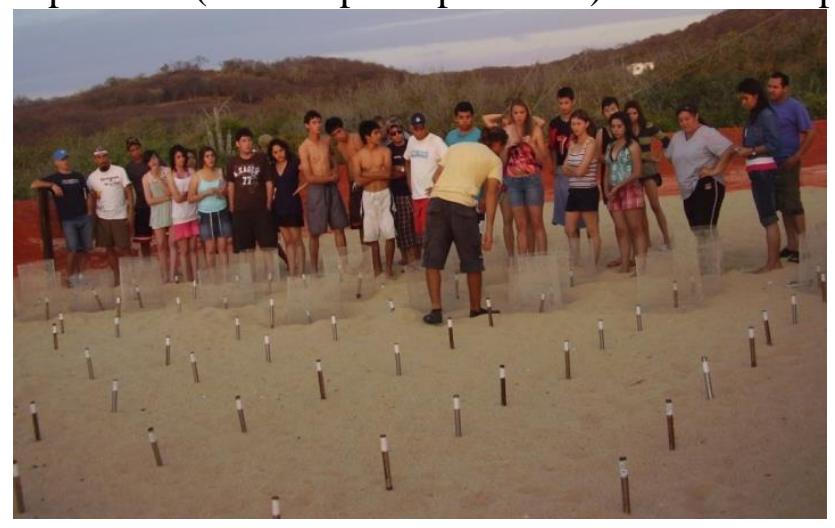

Figura 11: Actividades del programa

4. Se realiza el sembrado de nidos en corrales de incubación: control de temperatura y humedad, mediante la aplicación de riegos o colocación de techos de malla-sombra.

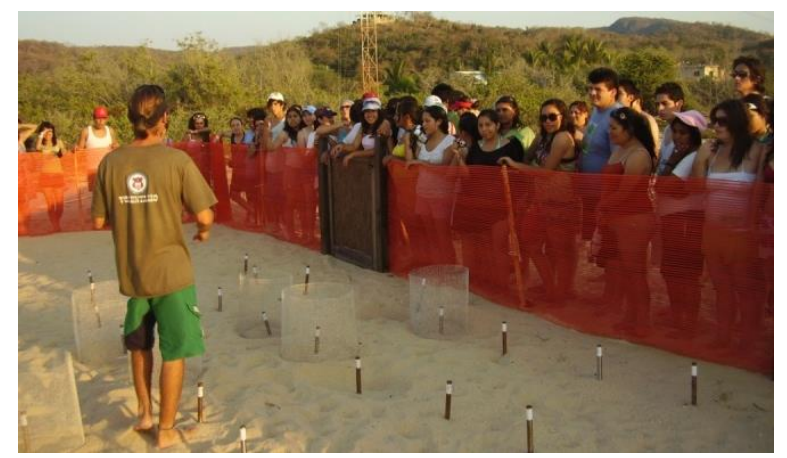

Figura 12: Explicación de las actividades. Elaboración propia

5. Cada año se construyen 4 corrales con una capacidad para la incubación de mil nidos aproximadamente.

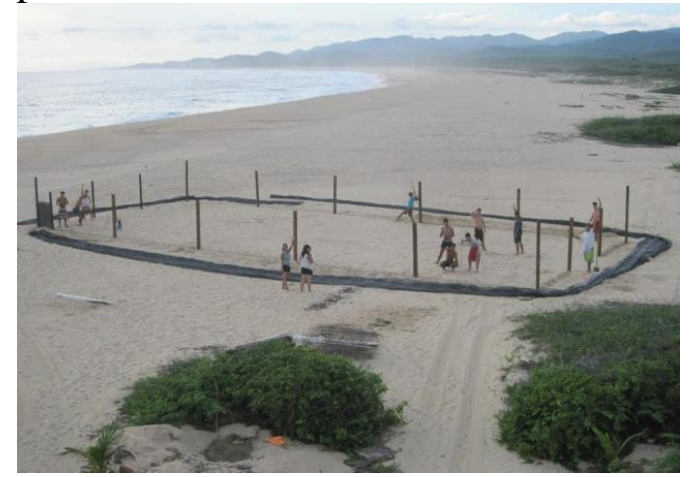

Figura 13: Corrales. Elaboración propia. 
6. Se da capacitación y talleres de educación ambiental continuos: Temas sobre la generación de energías alternas, así como factores atmosféricos relacionados con la anidación de las tortugas.

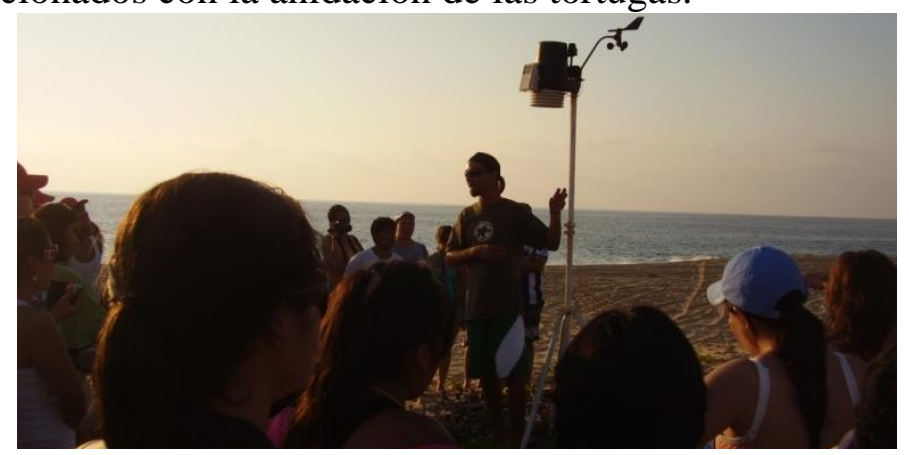

Figura 14. Capacitación en energías alternativas. Elaboración propia

7. Se desarrolla la aplicación práctica de los talleres durante la estadía de los grupos (colecta de nidos, trasplante y limpieza de las nidadas, liberación de crías).

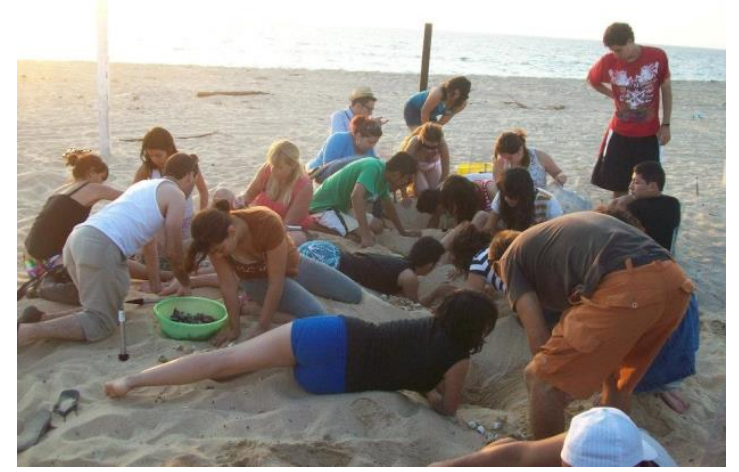

Figura 15: Actividades con los participantes. Elaboración propia

8. Se llevan a cabo trabajos de conservación en altamar.

9. Se trata de controlar la proporción sexual de poblaciones adultas, las cuales se logran a través de la temperatura de la arena.

10. Obtención de elevados niveles de concientización en comunidades pesqueras.

11. Protección, cura y ayuda de las especies dañadas o enfermas.

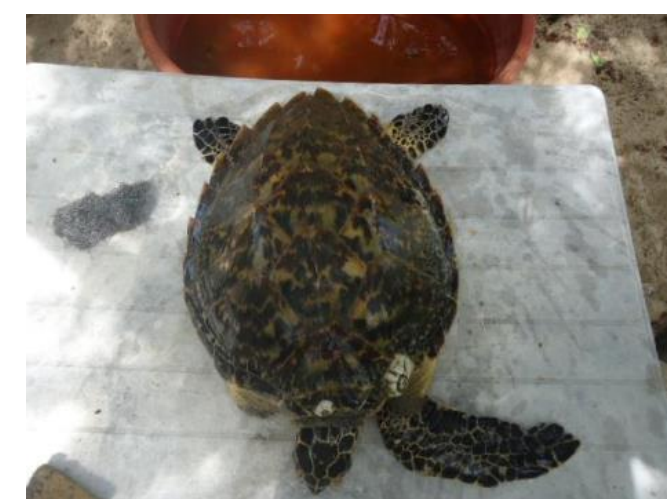

Figura 16: Muestra de un individuo. Elaboración propia 


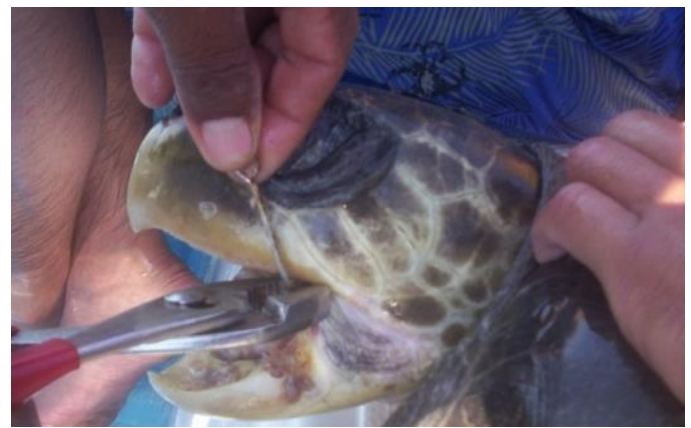

Figura 17: Cuidados a las tortugas. Elaboración propia

12. Se desarrolla el programa de manejo de fauna silvestre.

13. Se dan talleres de educación y concientización hacia el cuidado de la fauna

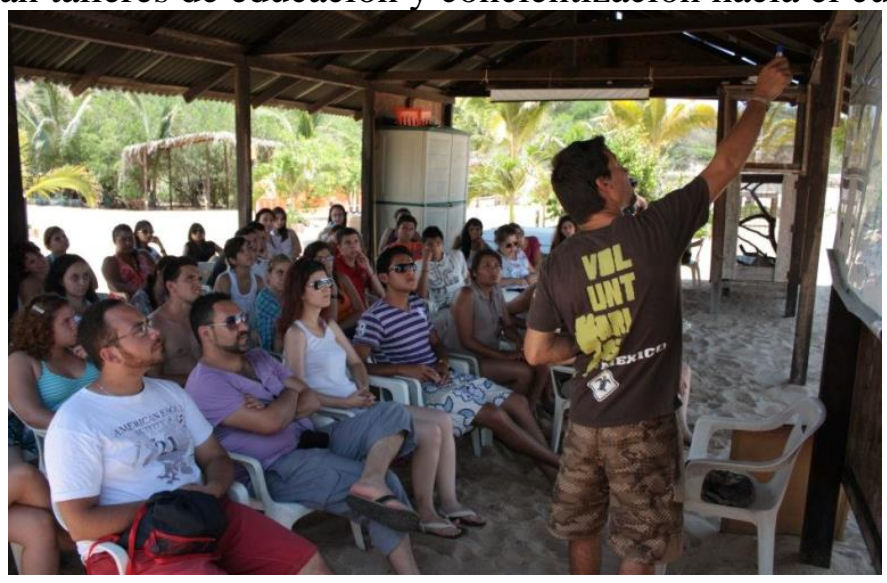

Figura 18: título de la imagen

14. Se realizan senderos interpretativos sobre naturaleza y medio ambiente.

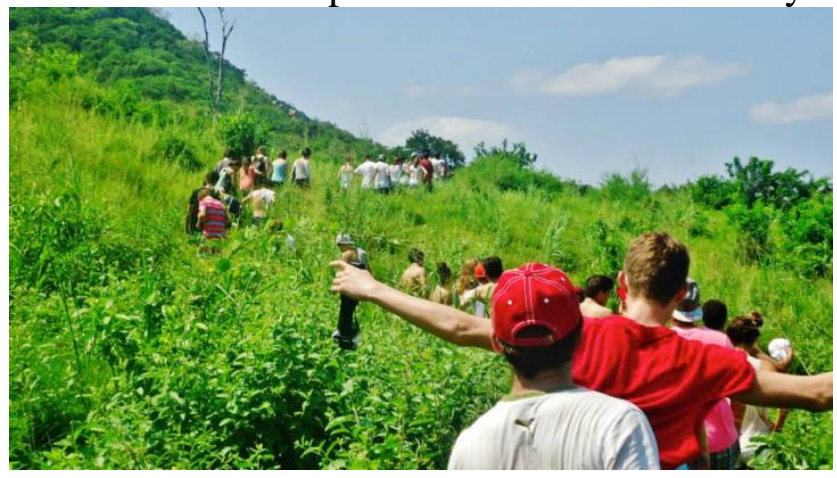

Figura 19: Gira de reconocimiento. Elaboración propia

15. Se llevan a cabo recorridos por cuevas, grutas, ríos y cascadas. 


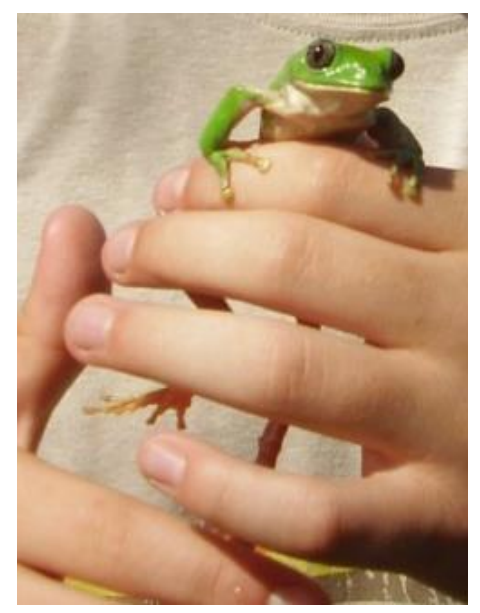

Figura 20: Muestra de la fauna. Elaboración propia

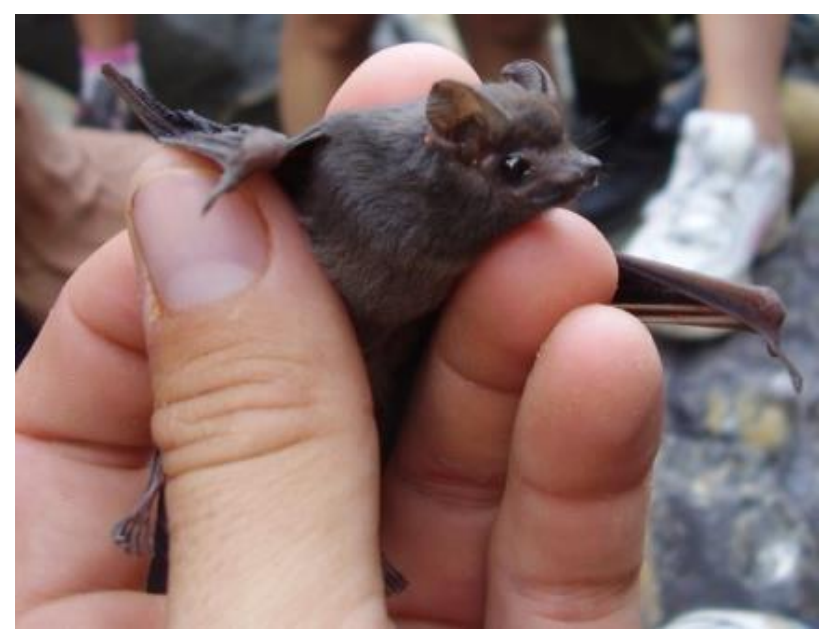

Figura 21: Muestra de la fauna. Elaboración propia

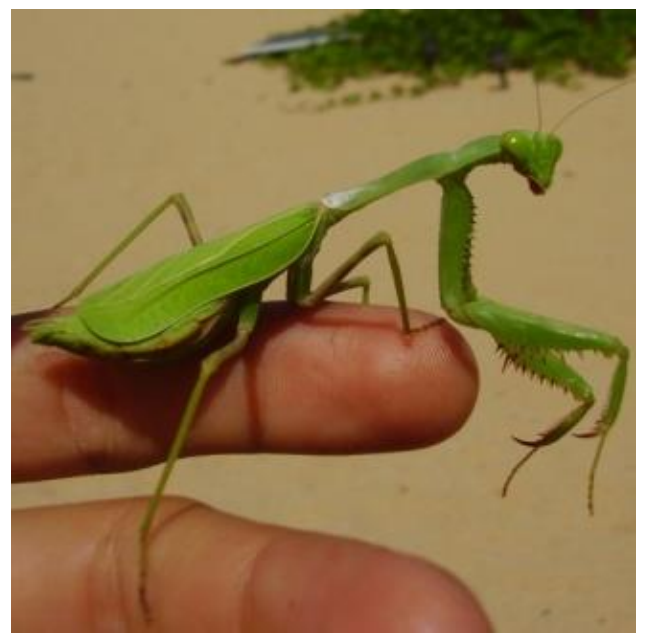

Figura 22: Muestra de la fauna. Elaboración propia

\section{Algunos datos como referencia}

Historial de 67 meses de labor ininterrumpida (Actualizado al 20 de enero de 2011) 
Patrullaje continuo a lo largo del año: De 1 a 4 vueltas según sea la incidencia de tortugas anidando:
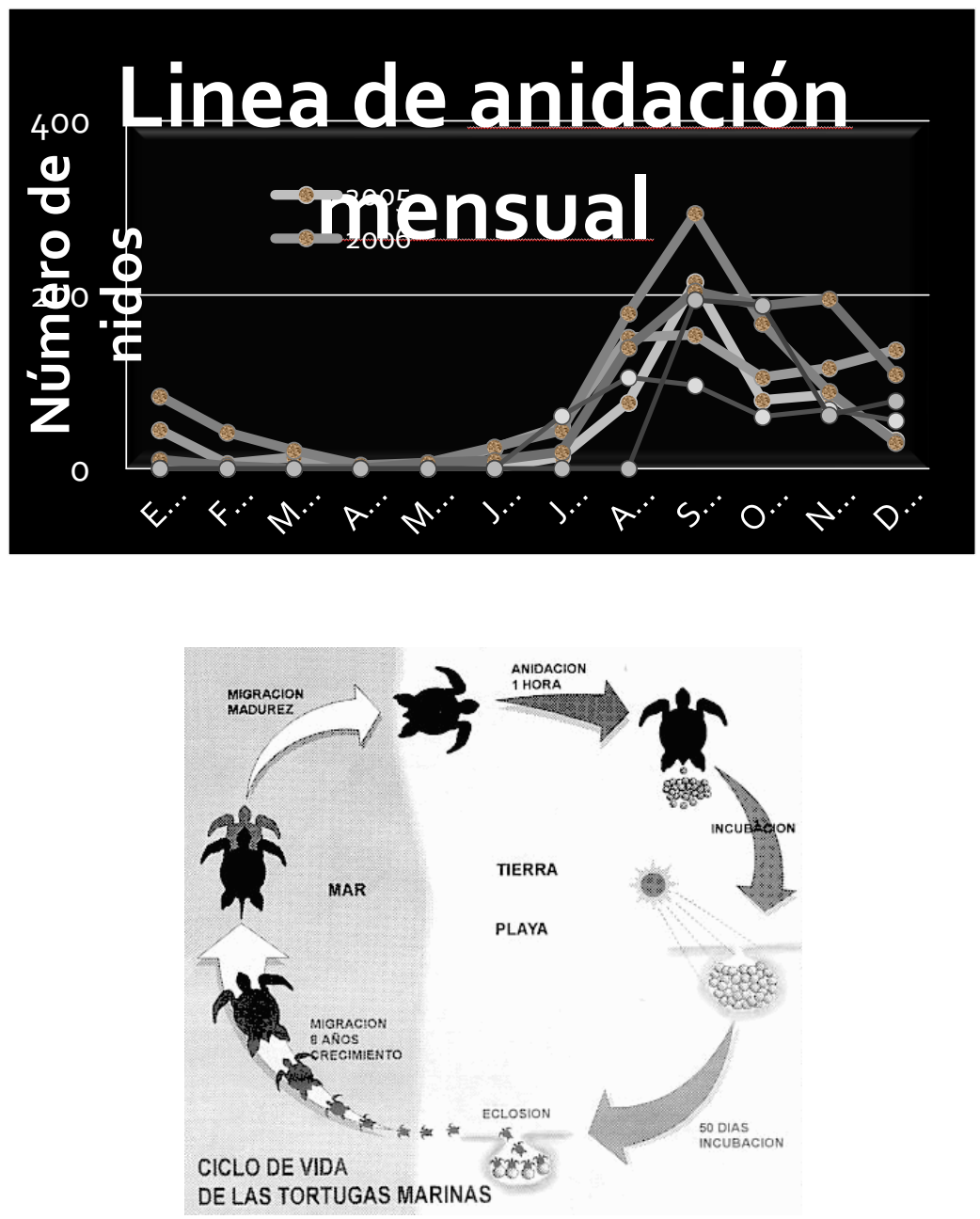

Figura 22: Ciclo de vida de las tortugas

\section{Personas que participan en el proyecto}

Tabla 2: Campamentos. Participantes en el 2010.

\begin{tabular}{|ccc|}
\hline Integrantes & $\mathbf{2 0 1 0}$ & TOTAL \\
\hline Número de estudiantes participando con grupos escolares: & 654 & 5,614 \\
\hline Número de escuelas participando: & 21 & 152 \\
\hline Número de maestros (guías) coordinando dichos grupos: & 48 & 317 \\
\hline
\end{tabular}

Fuente: Datos proporcionados por el coordinador responsable del Campamento.

\section{Conclusiones}


Entre las principales tenemos de que el campamento tortuguero de Mayto está realizando una gran labor ecológica, ya que desde el inicio de actividades de protección a la Tortuga marina en la zona, el índice de huevos de tortugas que llegan a eclosionar y que posteriormente son liberadas a mar abierto es alto (el 80\% de huevos de cada nido), así como la concientización sobre el manejo del medio ambiente y los procesos de contaminación se han reducido entre los habitantes, como consecuencia de pláticas y cursos impartidos.

Por lo anterior y de acuerdo a resultados de las entrevistas realizadas a los biólogos responsables del campamento, así como a sus estudios, análisis y control que llevan a cabo, se concluye que el numero de tortugas que llegan a la edad adulta ha aumentado considerablemente, después de la implementación y aplicación de programas de prevención y cuidado en los nidos rescatados, así como la concientización que se ha realizado entre los pescadores de Tehuamixtle, la cual ha sido mediante la explicación del impacto ambiental negativo que se lleva a cabo con la captura y sacrificio de éstas así como la contaminación marítima.

El crecimiento del proyecto refleja un beneficio en el cuidado y preservación de la tortuga marina, así como también la siembra y trasplante de mangle, se comprobó que existe una influencia positiva para los pobladores de Tehuamixtle y poblaciones aledañas respecto a la concientización en el cuidado del medio ambiente, además se percibe el impulso en el desarrollo económico tras el incremento en la demanda turística que participa en actividades de turismo ecológico sustentable aunado a la actividad pesquera.

Para finalizar, con relación a las actividades que se llevan a cabo en el campamento de Mayto, se recomienda:

- Continuar promoción de proyectos de prevención y protección de la tortuga marina.

- Impulsar programas para la reproducción segura de la especie.

- Promover el cuidado de huevos rescatados y sembrados dentro del campamento, para lograr un incremento el número de tortugas liberadas tras su eclosión.

- Ampliar programas de reforestación y actividades para el bienestar de la comunidad.

- Mantener continua concientización sobre el cuidado de flora y fauna entre habitantes y pescadores.

- Incentivar a los grupos turísticos con actividades de ecoturismo atractivas, mediante el involucramiento de los habitantes en la promoción de estos servicios.

- Generar estrategias alternativas de desarrollo local entre las comunidades.

- Platicar en reuniones e instruir a las personas integrantes de las comunidades rurales aledañas a la realización y práctica de servicios relacionados con el turismo sustentable.

\section{Referencias bibliográficas}

ARREGUI, Domingo Lázaro de. (1980). Descripción de la Nueva Galicia. Versión facsimilar. Segunda edición. Colección: Historia Serie: Crónicas de Occidente. Guadalajara, Jal., UNED, 1980.

BOTELLO Aceves, Brígida/ Magdalena Heredia Mendoza/ Raquel Moreno Pérez. Memoria del Municipio en Jalisco. Guadalajara, Jal. , UNED, 1987

BUDOWSKI, G. (2011), El ecoturismo en países tropicales: una actividad en plena expansión, pero también con problemas, recuperado en http://www.ecoportal.venezuela.com/, 30 de abril del 2011. 
CEVALLOS-Lascurain, H, (1987). Estudio de perfactibilidad socioeconómico del turismo ecológico en Sian Kaan Quintana Roo, SEDUE, México.

CEVALLOS-Lascurán, H., (1994). Estrategia Nacional de Ecoturismo. Secretaría de Turismo. México, DF.

COPPIN, L., (1992). "Ecoturismo y América Latina: una aproximación al tema en Estudios y Perspectivas en Turismo" 1(1), pp. 7-14.

FIGUEROA, H. H. G. (S. F.). Playa Mayto. En Vive $M x$. Recuperado de http://www.vivemx.com/destino/jalisco/playa-mayto, 23 de abril del 2011.

GUTIERREZ, Cristela (2010). ¿Quién protege a las tortugas en Jalisco? El Occidental. Recuperado de http://www.oem.com.mx/eloccidental/notas/ n1830202.htm, recuperado el 25 de abril del 2011.

HONEY, M., (1999). Ecotourism and Sustainable Development: Who Owns Paradise? Island Press, Washington, D.C.,p. 22-23

IINEGI, nstituto Nacional de Estadística y Geografía, (2005). Cabo Corrientes, Jalisco. Prontuario de información geográfica municipal de los Estados Unidos Mexicanos. Recuperado de http://mapserver.inegi.gob.mx/webdocs/prontuario/14020.pdf, 06 de mayo de 2011.

INEGI, Instituto Nacional de Estadística y Geografía, (2010). Censo de Población y Vivienda 2010, Cabo Corrientes, Jalisco. Información Nacional, por Entidad Federativa y Municipios. Recuperado de http://www.inegi.org.mx/sistemas/mexicocifras/default. aspx ?src=487\&ent=14, 07 de mayo del 2011.

INEGI, Instituto Nacional de Estadística y Geografía, (2010). Censos y Conteos de Población y Vivienda. Recuperado de http://www.inegi.org.mx/est/contenidos/Proyectos/ccpv/ default.aspx, 07 de mayo del 2011.

Instituto Nacional para el Federalismo y el Desarrollo Municipal, Gobierno del Estado de Jalisco (2005). Estado de Jalisco, Cabo Corrientes. Enciclopedia de los Municipios de México. Recuperado de http://www.elocal.gob.mx/work/templates/enciclo/jalisco/mpios/14020a.htm, 22 de abril del 2011.

International Ecotourism Society. Recuperado en http://www.ecotourism.org/what-isecotourism, recuperado el 25 de abril del 2011.

JANKA, H. (1996). Ecoturismo en Áreas Forestales. Gaceta Ecológica. Número 39.

LLAMAS González, I., (2011). Proyecto Campamento Tortuguero Mayto.

MAYTO, (2009), En Whikipedia, La enciclopedia libre. Recuperado de http://es.wikipedia.org/wiki/Mayto, 30 de mayo del 2011.

OMT. (2013). Panorama OMT del Turismo Internacional; edición 2013. UNWTO. 15 p. Madrid, España.

OROZCO Alvarado Javier, Quintero Santos José Lázaro, (2008), I. Impactos Socioculturales y Medioambientales del Turismo, en Orozco Alvarado Javier, Nuñez Martinez Patricia, Virgen Aguilar Carlos Rogelio, Desarrollo Turístico y Sustentabilidad Social, México, Ed. Miguel Angel Porrúa-Universidad de Guadalajara, CUCosta.

Políticas y programas de desarrollo: la experiencia de Cabo Corrientes, Jalisco; México. Recuperado de http://www.foroconsultivo.org.mx/eventos_realizados/7o _innovacion/presentaciones/mtro_macedonio.pdf, 28 de mayo del 2011.

SECTUR. (2001). Estudio estratégico de viabilidad del segmento de ecoturismo en México. 
SECTUR. (2011) ¿Qué es el turismo de naturaleza? http://www.sectur.gob.mx/work/sites/sectur/resources/LocalContent/15359/20/Que EsTurismoDeNaturaleza.pdf, recuperado el 25 de abril del 2011.

TEHUAMIXTLE, Jalisco. (s./f.). en Playas de México. Recuperado de http://playasmexico. com.mx/playa_mexico_ficha.php?id_rubrique=868, 03 de mayo del 2011.

The Ecoturism Society (1993 en Ascanio Guevara, Alfredo (2009)). "Turismo Sustentable: el equilibrio en el siglo XXI". México: Trillas.

WOOD, M. Ecotourism: Principles, Practices and Policies for Sustainability, http://www.unep.fr/scp/publications/details.asp?id=WEB/0137/PA

http://www.foro-mexico.com/jalisco/tehuamixtle-tehualmixtle/mensaje-192275.html

http://playasmexico.com.mx/llegar_playa.php?id_rubrique=891

http://mexico.pueblosamerica.com/i/tehuamixtle-tehualmixtle/

http://www.vivemx.com/destino/jalisco/tehuamixtle

http://www.costalegre.com/cabocorrientes.htm

http://www.foro-mexico.com/jalisco/tehuamixtle-tehualmixtle/clima-tiempo.html

http://app1.semarnat.gob.mx/dgeia/estadisticas_2000/estadisticas_ambientales_2000/03_Di mension_Ambiental/03_04_Biodiversidad/III.4.5/RecuadroIII.4.5.4.pdf 